\title{
Effective Benefit Program
}

\section{Suhartini*}

\section{Abstract}

Benefit Programs (BP) is the financial compensation provided indirectly to the employees, including 3 (three) categories, namely: income. protection Programmes, reimbursed time off and employee services and perquisites. BP offered a firm reflects the specific decisions made by managers. For companies, $B P$ is offered to strengthen the emengence of a sense of caring and belonging as a family on the employees themselves. For employees, BP is provided by the company can belp meet their physical and economic needs, and will ultimately spur performance. Therefore, $B P \mid$ can also be linked to individual performance and company performance. $B P$ is a major cost for employers and as a key element. of compensation that will affect the satisfaction of the employee. Today many companies develop creative $B P$, leaving $B P$ with the traditional concept of one-size-fits-all and offers the flexibility for employees to choose a BP that can meet the unique needs of each employee

Keywords: Benefit Programs and performance

\section{Pendahuluan}

Timbulnya persaingan global yang semakin kompetitif saat ini menyebabkan organisasi harus semakin menyadari pentingnya efisiensi dan efektivitas dalam mengelola sumber daya manusia (SDM) untuk memantapkan daya saing perusahaan. Pencapaian keunggulan bersaing melalui SDM haruslah didukung oleh SDM yang memiliki kemampuan tinggi, jarang dimiliki individu lain, sulit untuk ditiru dan dikembangkan secara tepat (Bohlander.\& Snell, 2004:3). Kemampuan membangun keunggulan bersaing ini sangat dipengaruhi oleh komitmen, partisipasi, moral kerja, motivasi, kompensasi, kepuasan kerja dan kinerja karyawan (Kini \& Hobson, 2002:605).

Kompensasi adalah semua bentuk penerimaan yang mengalir kepada karyawan dan timbul dari adanya hubungan kepegawaian (Kanungo \& Mendonca, 1992:2). Hubungan kepegawaian ini menunjukkan "exchange relationship" antara pengusaha dengan karyawan. Dalam pandangan ekonomi, kompensasi finansial dianggap sebagai dasar terwujudnya "exchange relationship" antara pengusaha dengan karyawan (Singh, Fujita \& Norton, 2004:230). Di era saat ini, dimana disain pekerjaan adalah tim, kompensasi

* Dosen Fakultas Ekonomi UII 
diberikan oleh perusahaan dengan tujuan : (1) mengembangkan usaha, (2) mendorong teamwork, (3) Meningkatkan hubungan antara kinerja dengan penghargaan, (4) meningkatkan moral kerja, (5) Mengefektifkan komunikasi dan (6) menciptakan lingkungan kerja yang kondusif (Zobal,' 1999:23)

Kompensasi yang sifatnya finansial merupakan bagian penting dari pengeluaran perusahaan, karena : (1) dalam suatu perusahaan manufaktur, biasanya kompensasi menghabiskan $50 \%-60 \%$ dari total biaya operasi dan (2) dalam perusahaan jasa, bagian kompensasi dapat mencapai $80 \%$ dari biaya keseluruhan (Kanungo \& Mendonca, 1992:4). Saat ini, insentif, reward dan recognition merupakan parameter kunci dari program motivasi yang harus dipertimbangkan perusahaan yang mengikat factor sukses organisasi dengan kinerja karyawan (Malik, dkk, 2010:62-70)

Salah satu bentuk kompensasi financial yang dibayarkan secara tidak langsung adalah benefit (Kanungo \& Mendonca, 1992:7). BP yang ditawarkan suatu perusahaan mencerminkan keputusan spesifik terkait benefit yang dibuat oleh manajer. Bagi perusahaan, benefit tersebut ditawarkan untuk, antara lain memperkuat munculnya sense of caring and belonging sebagai satu keluarga di diri para karyawan. Bagi karyawan, benefit yang diberikan perusahaan dapat membantu memenuhi kebutuhan ekonomi dan fisik mereka, dan pada akhirnya akan memacu kinerja. Oleh karena itu, pemberian benefit juga dapat dikaitkan dengan kinerja individu maupun kinerja perusahaan (Milkovich and Boudreau, 1997:541)

Tekanan persaingan berakibat pada sulitnya pembuatan keputusan terkait pemberian benefit. Di satu sisi, biaya tenaga kerja harus dikendalikan agar harga barang atau jasa yang dihasilkan menjadi kompetitif. Di sisi lain, persaingan di pasar tenaga kerja menyebabkan perusahaan harus menarik dan mempertahankan karyawan-karyawan produktifnya. Kondisi tersebut mengharuskan perusahaan untuk menyusun benefit program (BP) yang tepat bagi karyawan dan "bersaing" dengan BP yang ditawarkan perusahaan lain. 


\section{Pembahasan}

Klasifikasi Kompensasi

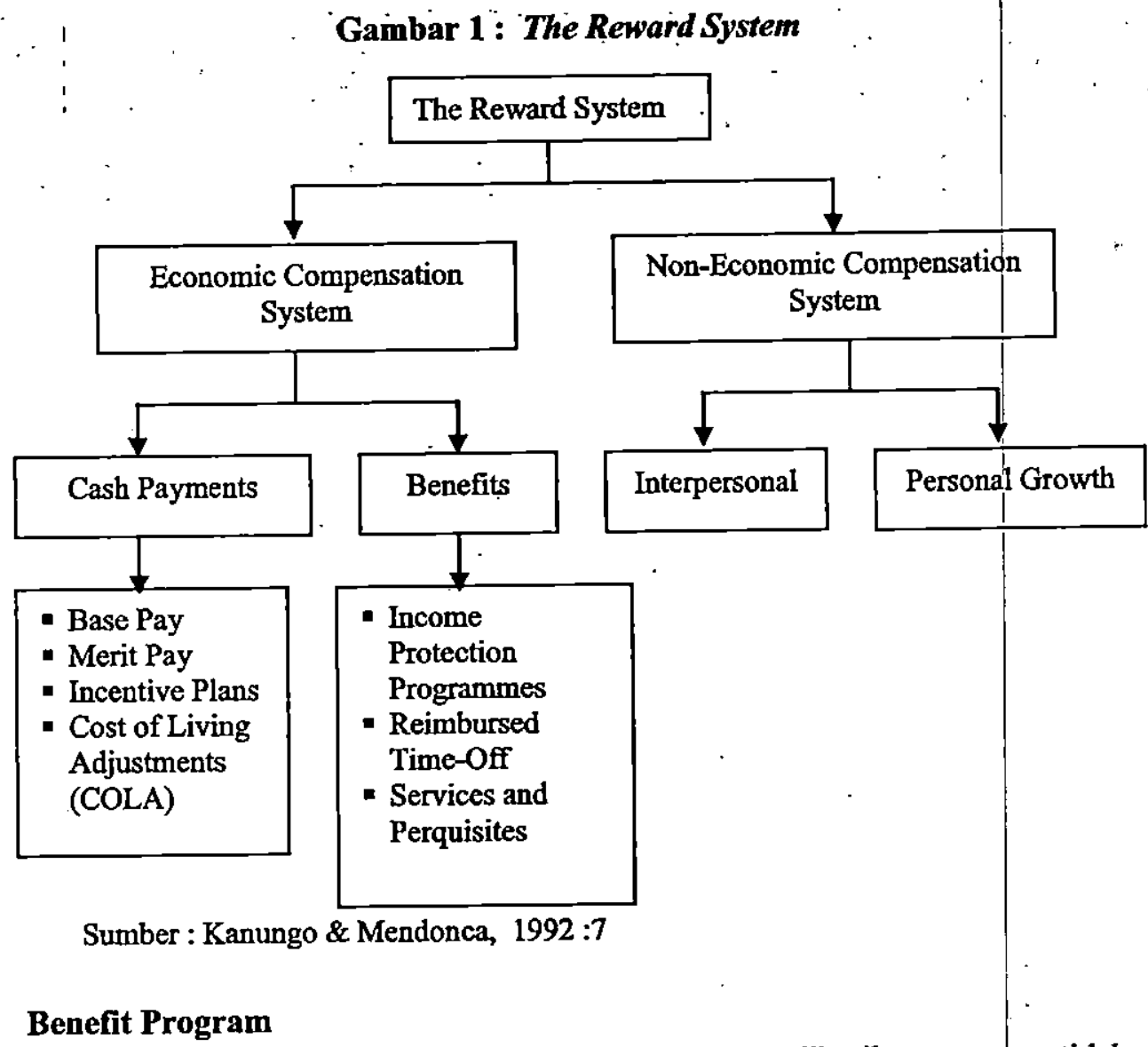

BP merupakan kompensasi financial yang diberikan secara tidak langsung kepada karyawan, meliputi 3 (tiga) kategori, yiatu : (1) program jaminan pendapatan (income protection programmes), (2) tetap dibayar waktu jauh dari pekerjaan (reimbursed time off) dan (3) employee services and perquisites (Kanungo \& Mendonca, 1992:7). Saat ini, benefit menjadi porsi utama dalam biaya tenaga karyawan. Pertumbuhan porsi BP dari total payroll pada tahun $1929(3 \%)$, pada tahun 1969 (31\%) dan pada tahun 1995 mencapai $40 \%$. Selain karena desakan kebutuhan, kondisi tersebut juga disebabkan oleh kebijakan pajak, di mana benefit merupakan pendapatan karyawan yang tidak dikenai pajak. (Milkovich and Boudreau, 1997:541). Di sisi lain; pertumbuhan porsi BP dari payroll mengisyaratkan bagi perusahaan untuk memprioritaskan pada pencarian pendekatan yang dapat menurunkan ataú mengelola BP secara efektif. 
BP diberikan perusahaa dalam rangka untuk meningkatkan daya saing (termasuk efektivitas biaya), mentaati peraturan perundang-undangan dan menyediakan pilihan yang disesuaikan dengan masing-masing karyawan, termasuk kebutuhan dan preferensi lainnya (Milkovich and Boudreau, 1997:541). Hasil survey yang dilaksanakan oleh Hewitt Associates Surveys pada tahun 1995, menunjukkan ranking of importance of different employee benefits, sebagai berikut : (1) medical, (2) dental, (3) paid time off, (4) pension, (5) sick leave, (6) life insurance, (7) short-term disability dan (8) long-term disability (Milkovich and Boudreau, 1997:550)

\section{Income Protection Programmes}

Income Protection Programmes (IPP) merupakan salah satu BP untuk melindungi pendapatan karyawan pada saat mereka kehilangan pekerjaan, tidak dapat bekerja karena sakit, cacat, kecelakaan kerja, maupun pension. Terdapat 2 (dua) tipe IPP, yaitu : dibiayai oleh pemerintah (bagi pegawai negeri) / perusahaan atau dibiayai oleh swasta. Bentuk IPP yang dapat disediakan oleh perusahaan adalah : unemployment insurance, workers'compensation, pension plan, private pension plan, group insurance programmes (Kanungo \& Mendonca, 1992:324-329).

- Unemployment insurance, menyediakan jaminan pendapatan saat kondisi tidak bekerja karena kehilangan pekerjaan (PHK).

- Workers'compensation, meliputi : pemberian kompensasi saat karyawan cedera, cacat maupun meninggal akibat kerja. Di Kanada, kompensasi ini disediakan oleh komisi kompensasi pekerja, di mana dananya merupakan dana iuran para pengusaha, yang besar-kecilnya iuran tergantung tinggirendahnya risiko kerja

- Private pension plan, mengikutsertakan karyawan dengan additional retirement benefits

- Group insurance programmes. Program ini relatif lebih ekonomis, biasanya ditawarkan dalam paket asuransi kesehatan, berupa jaminan pendapatan saat terjadi cacat tidak permanen atau kematian "bukan" akibat pekerjaan maupun pada karyawan yang tidak diasuransikan. Program ini banyak diterapkan pada pekerjaan dengan risiko tinggi, dengan besaran antara $66 \%$ $80 \%$ dari gaji dan dibayarkan setelah 120-180 hari dari kejadian sampai dengan karyawan dapat bekerja kembali atau sampai dengan usia pension.

\section{Reimbursed Time Off}

Yang dimaksud dengan time-off adalah semua kondisi di mana karyawan diijinkan untuk tidak bekerja, seperti : waktu makan siang, istirahat minum teh 
/kopi/merokok, libur tahunan, libur nasional/agama, libur pribadi, sakit, melahirkan (Kanungo \& Mendonca, 1992:330-331).

- Libur tahunan diberikan dengan tujuan untuk meningkatkan kepuașan karyawan terhadap kebutuhan istirahat dan rekreasi, sehingga menjadi lebih fit dan segar serta pada akhimya menjadi lebih bersemangat untuk mencapai kinerja yang lebih tinggi di masa yang akan datang. Di Kanada, libur tahunan diberikan umumnya selama 2 (dua) minggu. Akan tetapi ketentuan libur tahunan ini juga dipengaruhi oleh masa kerja karyawan.

- Bagi karyawan dengan masa kerja 9-12 tahun, karyawan berhak atas libur tahunan selama 4 (empat) minggu, bagi karyawan dengan masa kerja 1520 tahun, berhak atas libur tahunan selama 5 (lima) minggu, dan bagi yang bermasa kerja lebih dari 25 tahun, berhak atas libur tahunan selama . 6-7 minggu.

- Libur nasional/agama. Karyawan yang diminta bekerja pada saat libur nasional dan agama, berhak atas "gaji spesial" perhari sekitar $2-2.5$ kali dari lembur regular.

- Paid "personal days". Hal ini diberikan perusahaan dengan tujuan memberi kesempatan karyawan untuk pertemuan pribadi, keluarga dan tanggungjawab sosial lainnya. Bagi perusahaan dapat digunakan untuk mengadakan pertemuan tanpa gangguan terkait dengan tanggung jawab kerja, biasanya selama $(2-5)$ hari.

- Paid "sick leave" programmes. Umumnya, disediakan rata-rata 10 hari per tahun, karyawan diijinkan untuk tidak bekerja dengan alasan sakit. Hal ini tentu dengan syarat harus menyertakan surat keterangan dokter. Kebijakan yang dapat diterapkan terkait dengan sick leave dan pengendalian absen adalah : (1) pemotongan gaji pada hari pertama sakit dan (2) memberi hadiah bagi karyawan yang tidak menggunakan program ini dalam setahun.

\section{Employee Services And Perquisites}

Services \& perquisites dapat berbentuk : private health insurance plans, educational assistance, subsidized cafetarias, recreational facilities and programmes, parking privilages, discounts on company product and credit unions (Kanungo \& Mendonca, 1992:331-333).

- Private health insurance plans. Program ini bertujuan untuk melengkapi asuransi kesehatan yang telah ditanggung oleh negara/perusahaan. Bentuk program ini antara lain : layanan ambulan dan perawat untuk kondisi darurat, vision and hearing care, dan kemudahan mendapatkan resep obat.

- Educational assistance. Program ini dapat diperuntukkan bagi karyawan sendiri ataupun anak karyawan. Program ini diberikan dalam bentuk adanya penggantian biaya pendidikan maupun materi pengajaran dan dapat 
berupa pemberian kesempatan untuk belajar. Program ini kadang-kadang dibatasi dengan persyaratan bahwa pendidikan yang diambil harus memiliki kesesuaian dengan pekerjaan. Program ini juga dapat digunakan oleh pérusahaan untuk mempertinggi ketergantungan/ikatan karyawan terhadap perusahaan

- Subsidized cafetarias. Program ini biasa disediakan oleh perusahaanperusahaan besar, dalam bentuk : keanggotaan dalam klub fitnes, bowling, golf, dll

- Discount on company products . Program ini biasa dilakukan di perusahaan manufaktur atau barang/jasa konsumsi $\rightarrow$ contoh : karyawan toko retail dapat membeli produk dengan spesial diskon, karyawan institusi keuangan memberikan pinjaman dengan suku bunga pinjaman lebih rendah.

- Perquisites or "perks". Contoh dari program ini : tersedianya fasilitas mobil perusahaan, club membership, biaya perjalanan gratis bagi pasangan yang mendampingi dalam urusan bisnis perusahaan, tiket gratis untuk nonton film atau pertunjukan budaya.

\section{BP di Era Global}

BP merupakan biaya yang besar bagi pengusaha dan sebagai elemen kunci dari kompensasi yang akan mempengaruhi kepuasan dari sisi karyawan ( Charland, 2006:12-13). BP yang "populer" saat ini : (1) employee assistance programmes (EAPs), (2) Day-care, (3) Flex-time and (4) Employee Stock Ownership Plans (ESOPs).

1) Employee Assistance Programmes (EAPs)

Program ini berfokus pada rehabilitasi kecanduan alkohol maupun obat terlarang. Era sekarang, program ini berkembang meliputi juga konsultasi untuk stres kerja.

\section{2) Day-Care}

Perusahaan menyediakan fasilitas penitipan anak, yang dapat dikelola oleh perusahaan ataupun dikelola pihak lain. Program ini ditawarkan untuk merespon kondisi semakin meningkatnya perempuan bekerja di luar rumah. Keuntungan dengan diterapkannya program ini adalah : (1) menciptakan perasaan damai bagi karyawan perempuan, sehingga produktivitas dapat meningkat, (2) " menurunkan perputaran karyawan, (3) menciptakan keunggulan bersaing pada saat mencari tenaga kerja, (4) penghematan biaya penitipan anak bagi karyawan

3) Flex-Time

Flex-time program memberi kebebasan bagi karyawan untuk memulai maupun mengakhiri hari kerja, dengan tetap berorientasi pada produktivitas. Perusahaan menetapkan periode "core hours" dimana karyawan wajib 
hadir. Tujuan diterapkannya flex-time program adalah : (1) mendorong munculnya perilaku yang mendukung kepuasan kerja dan komitmen organisasi, dan (2) menyediakan waktu. lebih banyak bagi karyawan untuk urusan pribadi/keluarga/sosial dan pada akhirnya meminimalkan absen. Flex-time tidak akan sukses tanpa keterlibatan karyawan dalam mendisain dan mengimplementasikannya dan kerjasama dan dukungan dari middle management. Program ini akan semakin positif dampaknya, jika diberlakukan employee self-management. Kelemahan flex-time program adalah : (1) tidak cocok untuk perusahaan dengan proses kerja atau teknologi yang saling ketergantungan dan (2) meningkatnya biaya administrasi dan kesulitan saat jadwal bertentangan dengan aturan yang berkaitan dengan biaya lembur dan waktu istirahat

4) Employee Stock Ownership Plans (ESOPs)

ESOPs memberi hak kepada karyawan untuk membeli saham perusahaannya pada harga tertentu selama periode tertentu pula. Pada umumnya harga pembelian ini ditetapkan lebih murah daripada harga pasar pada saat dimulainya ESOP.

Program kepemilikan saham karyawan mendorong karyawan untuk mengembangkan rasa kepemilikan dan komitmen terhadap perusahaan. Di Amerika Serikat, karyawan yang mengikuti ESOP meningkat dari 4 juta orang pada 1980 menjadi lebih dari 10 juta pada 1999. Perusahaanperusahaan ini memiliki rata-rata produktivitas yang lebih tinggi dibandingkan dengan perusahaan-perusahaan yang tidak menerapkan ESOP (Noe, dkk, 2003:508).

Tujuan dari program ESOPs ini adalah : (1) memberikan penghargaan (reward) kepada seluruh karyawan, direksi, dan pihak-pihak tertentu atas kontribusinya terhadap meningkatnya kinerja perusahaan, (2) meningkatkan motivasi dan komitmen karyawan terhadap perusahaan karena mereka juga merupakan pemilik perusahaan, sehingga diharapkan akan meningkatkan produktivitas dan kinerja perusahaan dan (3) sebagai sarana program , sumber daya manusia untuk mendukung keberhasilan strategi bisnis perusahaan jangka panjang, karena ESOP pada dasarnya merupakan bentuk kompensasi yang didasarkan atas prinsip insentif, yaitu ditujukan untuk memberikan pegawai suatu penghargaan yang besarnya dikaitkan dengan ukuran kinerja perusahaan (Suhartini \& Muhammad Arief RS, 2007:17-33). Program kepemilikan saham perusahaan bagi karyawan juga bisa menumbuhkan perasaan identifikasi terhadap tujuan-tujuan organisasi (Long, 1998:110). Kepemilikan saham bagi karyawan dapat dengan cara : (1) Karyawan dapat membeli bursa saham secara langsung, (2) diberikan kepada mereka sebagai bonus, dan (3) dapat menerima saham pilihan, atau 
memperoleh bursa saham melalui pembagian keuntungan yang telah direncakan dan disusun oleh perusahaan. Bentuk utama employee stock plan, yaitu stock bonus plan, stock purchase plan dan stock option plan (Suhartini \& Muhammad Arief RS, 2007:17-33)

- Employee stock bonus plan. Perusahaan memberikan saham perusahaan pada karyawan secara gratis. Contoh : Di PT Telkom, saham jenis ini dikenal dengan nama saham perdana, yaitu saham perusahaan yang diberikan kepada karyawan secara gratis yang besarnya sesuai dengan jabatan karyawan.

- Employee stock purchase plan. Karyawan memberikan beberapa bentuk permbayaran langsung untuk mendapat saham ini. Karyawan biasanya tidak harus membayar harga pasar secara penuh (full market price) untuk saham-saham ini, dan ada banyak insentif yang ditawarkan perusahaan untuk meningkatkan jumlah pembelian saham oleh karyawan. Contoh : Di PT Telkom terdapat saham insentif, yaitu saham perusahaan yang dibeli oleh karyawan dengan harga di bawah harga pasar dan jumlah pembeliannya dibatasi sesuai dengan jabatan karyawan. Beberapa insentif ini meliputi beberapa bentuk subsidi atau harga diskon, atau sebuah program perpaduan (matching program). Dalam matching program, perusahaan memberikan selembar saham tambahan untuk masing-masing saham yang dibeli karyawan. PT Telkom juga memberikan saham tambahan bagi karyawan yang masih memegang saham perusahaan yang disebut dengan saham bonus. Saham bonus menupakan saham perusahaan yang berikan pada karyawan sebagai bentuk penghargaan atas masih dimilikinya saham perusahaan oleh karyaawan.

Agar kepemilikan saham karyawan (ESOP) ini mempunyai pengaruh terhadap sikap dan perilaku karyawan, terdapat hal-hal yang harus diperhatikan sebelum suatu perusahaan menerapkan BP dalam bentuk ESOPs adalah sebagai berikut : (Pierce, dkk., 1991:127)

a) Ownership expectations. Perlunya kesesuaian antara harapan karyawan dengan kepemilikan formal (dalam hal perolehan persamaan, informasi dan pengaruh) sehingga memperkuat kepemilikan psikologis.

b) Sense of legitimacy. Diperlukan terciptanya perasaan legitimasi kepemilikan yang kuat sehingga menimbulkan hubungan yang positif antara kepemilikan formal dan psikologis.

c) Management's philosophical commitment to employee ownership. Perlu adanya komitmen filosofis manajemen terhadap kepemilikan karyawan yang mencerminkan ESOP sebagai bagian sentral dalam 
filosofi manajemen dan strategi SDM serta merupakan bagian terpadu dari integritas dan budaya organisasi.

d) Financial orientation. Agar dihindari derajat pendekatan pekerja terhadap sistem kepemilikan karyawan terutama dengan harapan pembagian investasi. (memandang kepemilikan dalam perspektif instrumental) karena justru menyebabkan individu tidak akan mengalami kepemilikan secara psikologis.

e) Type of plan and context origin. ESOP sebagai sebuah bentuk renumerasi yang dalam konteks awalnya dibentuk dengan berpusat pada pekerja itu sendiri (sesuai komitmen filosofisnya). Bila hal ini dilaksanakan secara konsekuen akan lebih memberikan kepuasan terhadap karyawan dalam penerapan ESOP.

\section{Flexible Benefits}

Program kompensasi (termasuk BP) suatu organisasi tidak dapat diterapkan sepanjang masa, secara periodik perusahaan harus melakukan survei kepuasan terhadap kompensasi yang diberikan. Hal ini harus dilakukan karena, kompensasi merupakan alat untuk memotivasi kinerja karyawan. Seorang individu akan termotivasi dalam bekerja, jika imbalan yang ditawarkan merupakan sesuatu yang penting bagi pemuasan kebutuhannya.

Pada saat perusahaan akan mendisain BP baru, perusahaan harus mengetahui BP yang mana yang masih diinginkan dan BP mana yang sudah tidak diinginkan. Saat ini banyak perusahaan mengembangkan BP yang kreatif, meninggalkan BP dengan konsep tradisional yaitu one-size-fits-all dan menawarkan fleksibilitas bagi karyawan untuk memilih BP yang dapat memenuhi kebutuhan unik masing-masing karyawan (Charland, 2006:12-13)

Meskipun berbagai jenis benefit ditawarkan, tapi core cafeteria plan (contoh paling minimal : asuransi jiwa, asuransi kesehatan dan pensiun) adalah benefit yang paling umum ditawarkan. Flexible Benefits (FB) biasanya dilakukan dengan mengembangkan benefit minimal tersebut. Contoh: asuransi jiwa tambahan (misal : istri dan anak), Waktu liburan yang lebih panjang, asuransi dengan coverage lebih tinggi, layanan penitipan anak, dll. Keunggulan FB adalah dapat dicapainya kesesuaian yang lebih tinggi antara benefit yang ditawarkan perusahaan dengan kebutuhan (pilihan) karyawan. Sedangkan kelemahan dari penerapan FB ini adalah : (1) administrasi lebih rumit, termasuk dalam administrasi ini : komunikasi, konsultasi, pencatatan maupun sistem akuntansinya, (2) cepatnya perubahan pilihan yang mungkin terjadi (Milkovich. and Boudreau, 1997:553).

Di era global ini juga sudah mulai dipopulerkan benefits self-service (BSS). BSS merupakan terobosan untuk memberi kesempatan kepada karyawan 
untuk memilih BP yang sesuai. Karyawan harus dididik dalam memahami banyaknya BP - yang ada. Dengan kata lain, karyawan harus diajak berkomunikasi dan dilatihkan untuk memaksimalkan hasil dari BSS. Bagi pengusaha, penerapan BSS akan membutuhkan pertambahan waktu dan biaya dalam pengadministrasiannya. Oleh karena itu, perusahaan yang akan menerapkan BSS haruslah mengubah teknologi pendukungnya menjadi automate benefits administration (Crosby, 2005:56-58)

\section{BP Dan Bisnis Usaha Kecil}

Bisnis usaha kecil merupakan usaha yang mempekerjakan karyawan dengan jumlah kurang dari 500 orang. Peran BP di bisnis usaha kecil adalah untuk memotivasi dan mempertahankan karyawannya. Produktivitas karyawan akan terpengaruh di saat mereka merasa khawatir terkait dengan masalah keuangan yang dihadapinyạ. Terdapat 5 hal yang harus dipertimbangkan apabila usaha kecil menerapkan non-medical benefit program dengan hasil yang maksimal : (Anonymous, 2010)

1. Manage costs for dental, disability, and life insurance. Hal ini akan meningkatkan loyalitas karyawan. Banyak pengusaha usaha kecil tidak mengakui hal itu. Di sisi lain, karyawan sangat yakin bahwa BP sangat mempengaruhi loyalitas dirinya terhadap pengusaha. Agar BP lebih efektif dampaknya, disarankan BP, misal dental insurance diberikan berdasarkan kondisi nyata hasil observasi dan focus pada usaha pencegahan, sehingga meningkatkan kemanfaatan dan "value" bagi karyawan.

2. Deliver budget-conscious wellness programs. Hal ini akan meningkatkan produktivitas dan dapat membantu mengendalikan biaya. Wellness program diyakini akan mampu menurunkan biaya medis. Wellness program merupakan program pencapaian kesehatan mental dan fisik melalui program kemajuan kesehatan individual. Oleh karena itu perlu dukungan budaya sadar kesehatan untuk jangka panjang, seperti : penyuluhan hidup yang sehat, kesadaran untuk tidak merokok, diberlakukannya 1 hari dalam setiap minggu sebagai hari olah raga.

3. Help employees become financially secure and support productivity goals at the same time. Produktivitas karyawan sangat terpengaruh saat karyawan sedang menghadapi masalah keuangan. Bisnis usaha kecil disarankan bekerja sama dengan institusi keuangan local untuk membantu mengatasi kebutuhan keuangan karyawan, rencana pension, memberi fasilitas pada karyawan untuk mengakses web institusi penyedia jasa keuangan.

4. Simplify benefits communications for greater benefits effectives. Informasi mengenai benefits akan secara efektif memahamkan karyawan mengenai BP. Pemberian informasi ini dapat melalui berbagai saluran, menggunakan 
jargon, maupun melalui pesan-pesan yang relevan dengan tahap-tahap kehidupan manusia. Pengusaha bisnis usaha kecil harus juga mau mendengarkan dan mempelajari apa yang dikehendaki karyawannya, sebelum dilakukan launching BP melalui suatu campaign program.

5. Leverage small business workplace advantages for increased worker loyalty. Secara normative, penerapan BP akan memberi keunggulan dalam

. bentuk peningkatan toyalitas. Hal ini membutuhkan dukungan budaya perusahaan dengan lingkungan kerja yang seimbang antara kehidupan kerja dan .kehidupan pribadi.

\section{Penutup}

Menutup tulisan ini, ada satu hal yang tidak boleh dilupakan pada saat suatu perusahaan mendisain program kompensasinya (termasuk BP) adalah masalah proses. Masalah proses ini meliputi pelibatan karyawan dalam penyusunan BP dan komunikasi terkait dengan kebijakan BP. yang diambil. Komunikasi merupakan the soul of the workplace. Dengan komunikasi yang baik, diharapkan karyawan akan memahami BP apa yang ditawarkan oleh perusahaan, kemudian karyawan akan pelakukan penilaian terhadap BP dan akan diaktualisasikan dalam perilaku kinerjanya. Karyawan tidak hanya akan menerima hasil akhir disain BP saja. Tetapi karyawan juga harus diajak berperan aktif dalam proses disain BP. Karyawan akan mengemukakan apa yang dibutuhkannya dan akan memahami mengapa perusahaan memutuskan BP tertentu. Hal ini akan meningkatkan kepercayaan karyawan terhadap perusahaan dan pada akhirnya akan meningkatkan komitmen dan kinerja karyawan . (Kalbfleisch \& White, 1998:20-34). 


\section{DAFTAR PUSTAKA}

Anonymous, 2010. Metlife Study Highlights Cost-Effective Strategies Small Business ${ }^{-}$Can Use to Build Competitive Benefits Program and Help Improve Satisfaction, Busines Wire, New York.

Bohlander, George \& Snell, Scott, 2004. Managing Human Resources, Thomson South-Western, USA.

Charland, Brent., 2006. Developing Innovapost's Cost-Effective Structure, Strategic HR Review: Vol 5, Iss 3, p 12-13.

Crosby, Amy. 2005. Communication : A Key to Effective Benefits SelfService, Workspan: Vol 48, Iss 3, p 56-58.

Kalbfleisch, Robin and White, Janet., 1998. $1^{\text {st }}$ Annual Communication Awards (Canada's Most Effective Pension and Benefits Plan Communication Campaigns, Benefits Canada: Vol 22, Iss 6, p 20-34

Kanungo, Rabindra N. \& Mendonca, Manuel. (1992). “Compensation: Effective Reward Management”. Butterworths, Canada.

Kini, Ranjan B. \& Hobson, Charles J. (2002). "Motivational Theories and Succesful Total Quality Management". International Journal of Management. Poole:Vol 19, Iss 4, p 605.

Long, Richard J., (1998) Compensation in Canada: Strategy, Practice and Issue, International Thomson Publishing (ITP Nelson), Canada.

Malik, Muhammad Imran., Bibi, Shagufta, Rahim, Saddam Hussain., 2010. Non-Financial Measures of Layoff Survivors'satisfaction, Interdisciplinary Journal of Contemporary Research in Business: Vol 2, Iss 8, p 62-70.

Milkovich , George T., and Boudreau, John W., 1997. Human Resource Management, Richard D. Irwin, USA.

Mulligon, John J Jr, 1988. Defined-Contribution Plans Continue the Trend Toward Unbundling, Pension Management; Aug, 24, 8, 339.

Noe, Raymond A., dkk, (2003) Human Resources Management: Gaining A - Competitive Advantage, McGraw-Hill Inc, New York.

Pierce, Jon L., Stephen A. Rubenfeld, and Susan Morgan, (1991) Employee Ownership: A Conceptual Model of Process and Effects, Academy of Management Review, Vol. 16, p 127.

Singh, Douglas, Frank Fujita, \& Steven D. Norton. (2004). "Determinants of Satisfaction with Pay among Nursing Home Administrators". Juornal of American Academy of Business Cambridge, Hollywood:Vol 5, p 230.

Suhartini dan Muhammad Arief Rachman Soeyitno, 2007. Pengaruh Jenis Kepemilikan Saham ESOP (Employee Stock Ownership Plan) Oleh 
Karyawan Terhadap Komitmen Organisasi Kantor PT. Telkom Divre VI Banjarmasin, Ventura: Vol 10, No 1, p17-33.

Zobal, Cheryl., 1999. The "Ideal" Team Compensation System, Team Performance Management: Vol 5, Iss 1, p23. 